\title{
The Effect of Various Zeolites as an Adsorbent for Bioethanol Purification using a Fixed Bed Adsorption Column
}

\author{
Mahmud Sudibandriyo ${ }^{1 *}$, Fadhila Azzahra Putri ${ }^{1}$ \\ ${ }^{1}$ Department of Chemical Engineering, Faculty of Engineering, Universitas Indonesia, Kampus UI Depok, \\ Depok 16424, Indonesia
}

\begin{abstract}
The depletion of fossil energy sources has increased the demand for renewable energy. Bioethanol, which is a type of biofuel, can be used as a gasoline mixture, resulting in cleaner combustion with higher octane values as compared to conventional fuels. For bioethanol to be used as a gasoline mixture, two purification steps are required. Difficulties in the ethanol purification process are caused by the azeotrope condition of the ethanol-water mixture. To remove water from the mixture in azeotropic conditions, advanced technology is necessary. One method for separating ethanol and water that is both economical and effective is the adsorption process. This study observed adsorbent performance during a continuous adsorption process through a fixed bed column with different ethanol influent concentrations. Synthetic zeolites $3 \mathrm{~A}$ and $4 \mathrm{~A}$ will be examined as potential adsorbents because they have properties that result in a high adsorption capacity, they are not easily saturated, they have high selectivity, and they are easy to regenerate. This study was carried out under the bed operation condition of atmospheric temperature and pressure $\left(20^{\circ} \mathrm{C}\right.$ and $\left.1 \mathrm{~atm}\right)$, with a $50 \% \mathrm{v} / \mathrm{v}$ and $10 \% \mathrm{v} / \mathrm{v}$ ethanol inlet concentration, which has a $10 \mathrm{ml} / \mathrm{min}$ flow rate. The results of this study are presented with a breakthrough curve, which is used to analyze adsorption performance by determining the highest ethanol effluent concentration, the adsorption capacity, and the effective adsorption time. The zeolite $3 \mathrm{~A}$ adsorbent, which has a larger surface area and a pore diameter that is closest in size to that of water molecules, was found to have better adsorption performance, resulting in higher ethanol purity, higher adsorption capacity, and a longer saturation time as compared with the adsorption process of zeolite 4A.
\end{abstract}

Keywords: Breakthrough curve; Continuous adsorption; Ethanol-water; Zeolite adsorbent

\section{Introduction}

Environmental issues and energy security are concerns driving the increasing demand for renewable energy that is environmentally friendly and sustainable. It has been predicted that fossil energy sources will run out within the next 40-50 years (Vohra et al., 2014). The depletion of fossil energy sources could cause a global energy crisis, resulting in the disruption of economic growth. Biofuel is a promising, renewable energy source because of its material availability. One biofuel type that is commonly used to enhance gasoline performance is bioethanol. Bioethanol derived from natural ingredients that are rich in carbohydrates is used as an additive in gasoline fuels. It has a high-octane value, so mixing bioethanol and gasoline can improve engine performance. 
In addition, the oxygen content in bioethanol is higher than the oxygen content in gasoline fuels (Yuksel and Yuksel, 2004). As a result, the combustion of bioethanol is cleaner than that of pure gasoline. To be used as gasoline fuel additive, bioethanol must first be purified.

Producing bioethanol with a high level of purity is difficult because the purification process must be carried out in two stages, and there is an azeotrope state between ethanol and water. Water must be removed from the bioethanol-fuel mixture because it can separate from the fuel due to its density, forming two different layers. There are several technologies that can be used to increase the purity of bioethanol, including advanced distillation, pervaporation, and adsorption (Frolkova and Raeva, 2009). Advanced distillation technology uses additional chemicals to break down the azeotropic state between water and ethanol, while pervaporation technology uses a membrane to separate ethanol and water. A study comparing various ethanol dehydration methods found adsorption technology to be attractive due to its low energy demand for separation, its operational stability, and its high productivity (Sudibandriyo et al., 2015). Currently, adsorption is one of the technologies that is widely used in both the initial and final stages of purification. Adsorption is a separation process in which certain components of a fluid phase are transferred to the surface of a solid adsorbent. Continuous adsorption is a process in which adsorbate is poured continuously onto a bed (porous material) until the solid is nearly saturated and the desired separation can no longer be achieved (McCabe et al., 1993). Continuous adsorption on porous materials, when compared with other ethanol dehydration methods, was found to be attractive for its low energy demand for separation, its operational stability, and its relatively low operating cost (Sudibandriyo et al., 2015).

There are several kinds of adsorbents that are commonly used in adsorption processes; zeolite is one adsorbent that is typically used to separate ethanol-water mixtures. Zeolites are aluminosilicate crystals from groups IA and IIA (sodium, potassium, magnesium, and calcium), with a tetrahedral structure that provides cavities that can be occupied by cations and water molecules and allows for reversible cation exchange and dehydration. In general, zeolites consist of three components: interchangeable cations, alumina silicate framework, and water content. Zeolite is often used as an adsorbent because it has a high adsorption capacity, is not easily saturated, has high selectivity, and is easy to regenerate (Laksmono et al., 2018). Synthetic zeolite is developed in laboratories to meet the specifications and structure required to be a molecular sieve. The pores on the surface of synthetic zeolite are uniform in size, which facilitates an effective adsorption process. There are various types of zeolites that can be distinguished by the crystal structure of their aluminosilicate. Not all zeolites have the ability to adsorb water; it depends on their Si/Al ratio and the type of cation contained in their aluminosilicate bond (Kulprathipanja, 2010). Based on the research, zeolites with a lower $\mathrm{Si} / \mathrm{Al}$ ratio tend to be hydrophilic, while zeolites with a higher $\mathrm{Si} / \mathrm{Al}$ ratio tend to be hydrophobic (Kusrini et al., 2019). The Si/Al ratios in zeolites that have hydrophilic properties ranges from low to medium. The type of cation contained in the zeolites affects the water adsorption, where zeolites with monovalent cations, such as sodium and potassium, have better potential to attract water than zeolites that contain bivalent cations (Yamamoto et al., 2012). Zeolite selectivity for water is influenced by pore diameter and surface area.

Based on the literature exploring the potential of adsorption technology and the effectiveness of zeolite as an adsorbent to separate ethanol-water mixtures, this study will examine the effect of various zeolite types on adsorption effectiveness using a breakthrough curve to determine the highest ethanol effluent purity, the adsorption capacity, and the effective time. The breakthrough curve is used to model the continuous 
adsorption process by observing changes in concentration over time. From this curve, we can determine the difference in adsorbent performance under several operating conditions, with differences in the adsorbate concentration, flow rate, column dimension, amount of adsorbent, and temperature (Chen et al., 2012). Experiments will be conducted using the continuous bed adsorption column, where the adsorbate and adsorbent will be brought into contact such that that adsorbent can adsorb optimally until it reaches its saturated state. By applying the continuous adsorption process, the results of this study will be more applicable to real-life situations since continuous adsorption can be used to purified large amount of bioethanol.

\section{Methods}

\subsection{Column and Material Preparation}

The adsorption column dimension used in this research was calculated using the following equation:

Adsorbent needed $=$ amount of water removed $\times$ adsorbent's adsorption capacity

where the zeolite's adsorption capacity is $0.10044 \mathrm{ml}$ of water/gr zeolite adsorbent (Laksmono et al., 2018). The column volume is then determined using a bulk adsorbent density that has a value of $700 \mathrm{~kg} / \mathrm{m}^{3}$. From the calculation, it is determined that the adsorption column has a two-inch diameter and a one-meter height.

The materials used in this research were ethanol and zeolite adsorbents. The ethanol was from PT. Brataco, Jakarta and was technical grade with a purity of $96 \% \mathrm{v} / \mathrm{v}$. To obtain various ethanol purity levels $(95 \%, 50 \%$, and $10 \% \mathrm{v} / \mathrm{v})$, highly concentrated ethanol had to be diluted with distilled water. As much as $6000 \mathrm{ml}$ ethanol in each level of purity was prepared. Before it was used for column feed, the ethanol purity had to be analyzed with a density meter.

Synthetic zeolites that have hydrophilic properties (zeolites $3 \mathrm{~A}$ and $4 \mathrm{~A}$ ) were used in this study. They had a particle diameter of 3-5 $\mathrm{mm}$ and were purchased from Lioning Alger Import and Export Trade Co, China. To use zeolite adsorbent effectively, it should be heated in an oven at $250^{\circ} \mathrm{C}$ for 2 hours to remove the water content. The physical properties of each adsorbent used inside the column were analyzed with BET Micromeritics TriStar II. In this research, physical properties, such as the adsorbent's surface area and pore diameter, were obtained from a study conducted by Al-Asheh et al. (2004).

\subsection{Adsorption Process}

The adsorption process was conducted by pouring ethanol into the adsorption column, which had been filled with adsorbents. The flow rate of the ethanol was $10 \mathrm{ml} / \mathrm{min}$ at atmospheric temperature and pressure $\left(20^{\circ} \mathrm{C}\right.$ and $\left.1 \mathrm{~atm}\right)$. The duration of the study was 5 hours, and samples of the ethanol effluent were taken every 15 minutes or 21 times total throughout the adsorption process. The samples were then analyzed using a density meter to determine the concentration. This data is presented in the form of a breakthrough curve $\mathrm{Co} / \mathrm{Ci}$ vs time, where $\mathrm{Co}$ is the water effluent concentration and $\mathrm{Ci}$ is the water influent concentration. The continuous adsorption scheme is displayed in Figure 1. As much as 6000 $\mathrm{ml}$ of diluted ethanol in specific concentrations was placed in a storage tank. The ethanol entered the downflow adsorption bed from the top with the help of a peristaltic pump. To maintain the ethanol flow at $10 \mathrm{ml} / \mathrm{min}$, a bypass and ball valve was installed after the pump was put in. 


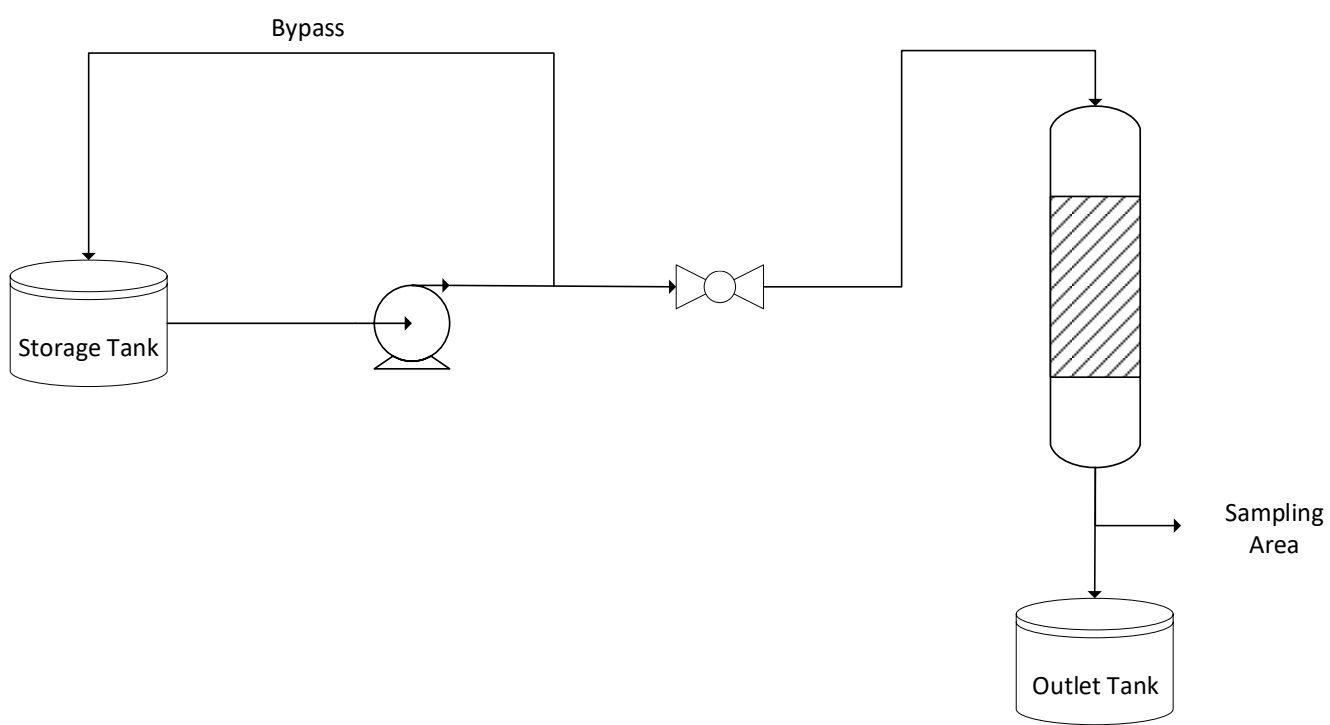

Figure 1 Scheme of continuous adsorbent process with zeolite adsorbent

\section{Results and Discussion}

\subsection{The Effect of Ethanol Influent Concentration}

The first bioethanol separation using an adsorption process was conducted with a bed packed with zeolite $3 \mathrm{~A}$ and an ethanol influent above the azeotrope state $(>95 \%)$, which was at $95.3 \%$. The experiment lasted 165 minutes, and 12 ethanol effluent concentration samples were taken. The samples were then processed into a breakthrough curve, as shown in Figure 2.

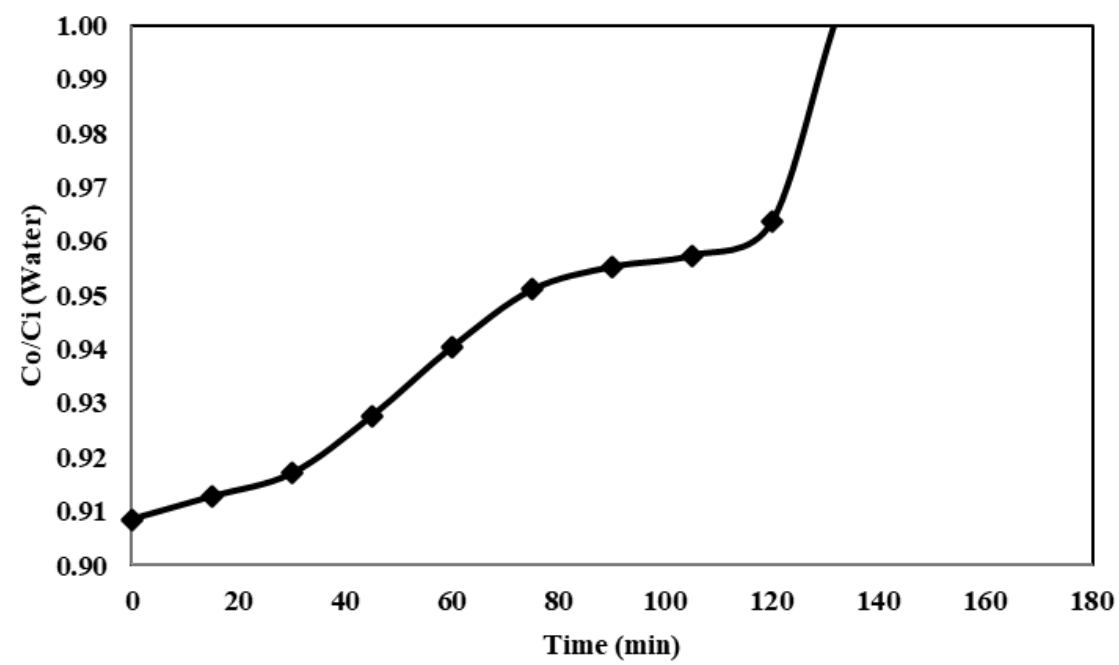

Figure 2 Breakthrough curve of adsorbent zeolite $3 \mathrm{~A}$ variation at ethanol influent concentration of $95 \%$

The highest ethanol purity that was achieved in the first experiment was $95.73 \% \mathrm{v} / \mathrm{v}$, which occurred when the ethanol first came out of the column. The purity of the ethanol effluent gradually decreased until it reached its initial purity $(95.3 \% \mathrm{v} / \mathrm{v})$ in the 120 th minute. It can be concluded that in the first experiment, there was an insignificant increase in the ethanol purity of the effluent so that effective time or breakthrough point can't be define. Effective adsorption is the phase where the adsorbent can adsorb the adsorbate optimally. The effective adsorption time is calculated from the time the ethanol effluent 
starts to come out of the adsorption column $(\mathrm{t}=0)$ until the time when the ethanol effluent concentration begins to decrease $(\mathrm{t}=\mathrm{n})$. The point at which the effective adsorption phase ends is called the breakthrough point. This phenomenon can be explained by Fick's first law, as expressed in the equation below

$$
\mathrm{J}_{\mathrm{Ay}}=-\mathrm{D}_{\mathrm{AB}} \frac{\mathrm{dC}_{\mathrm{A}}}{\mathrm{dy}}
$$

where $\mathrm{J}_{A y}$ is the mass transfer flux, $\mathrm{D}_{\mathrm{AB}}$ is the diffusivity value, and $\frac{d C_{A}}{d y}$ is the concentration gradient. Based on Fick's first law, the mass transfer flux is influenced by the diffusivity value and the concentration gradient of the substance. Where the substance concentration gradient acts as the main driving force, the greater the concentration gradient between the adsorbate and the adsorbent, the greater the mass transfer flux will be (Laksmono et al., 2017). The ethanol concentration in the first experiment was much higher than the water concentration. In this condition, there were more ethanol molecules, which led to a higher ethanol concentration gradient between the adsorbent and adsorbate. As a result, more ethanol molecules were adsorbed because the sheer volume of them outweighed the selectivity for water molecules of the absorbent. The insignificant increase in ethanol purity resulted in a breakthrough curve that does not align with the theory in the literature, as there is no breakthrough point on the curve. This can be seen in Figure 2.

Subsequent experiments were conducted by increasing the water concentration, since water acts as adsorbate in this study. This was conducted according to Langmuir's theory, where the amount of adsorbate adsorbed is proportional to the influent concentration. The adsorption process was carried out with both adsorbents $3 \mathrm{~A}$ and $4 \mathrm{~A}$, using the same flow rate, $10 \mathrm{ml} / \mathrm{min}$, as the first study. The ethanol entered the column with concentrations of $50 \% \mathrm{v} / \mathrm{v}$ and $10 \% \mathrm{v} / \mathrm{v}$. Samples of the ethanol output were taken every 15 minutes for 300 minutes to determine the concentration. The breakthrough curve from the second experiment conducted with adsorbents $3 \mathrm{~A}$ and $4 \mathrm{~A}$ is displayed in Figure 3.

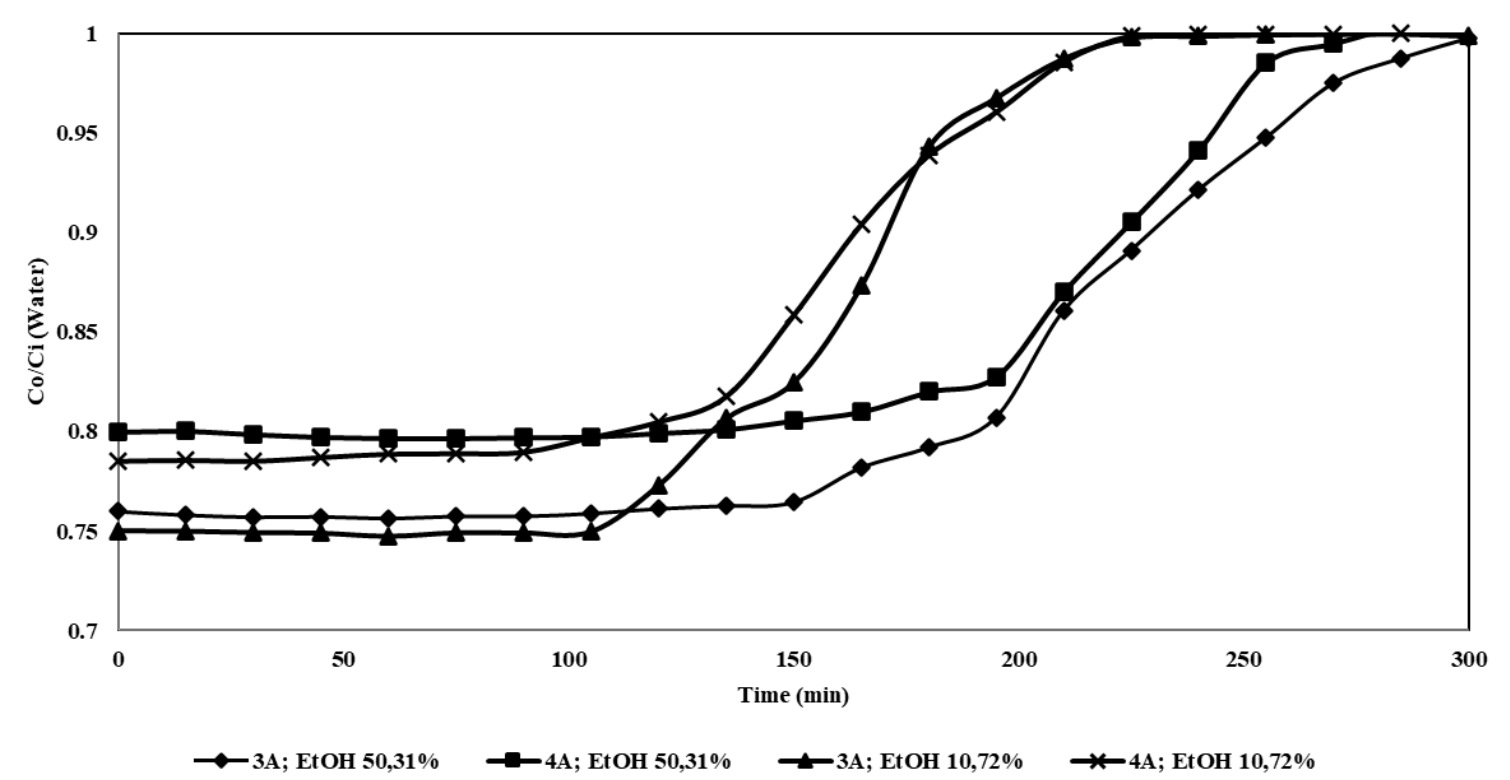

Figure 3 Breakthrough curve of adsorption process of adsorbent zeolites $3 \mathrm{~A}$ and $4 \mathrm{~A}$ at ethanol influent concentrations of $50 \% \mathrm{v} / \mathrm{v}$ and $10 \% \mathrm{v} / \mathrm{v}$

In the second experiment, which used an ethanol influent concentration of $50.31 \% \mathrm{v} / \mathrm{v}$, the effective adsorption process lasted for 150 minutes and reached the highest ethanol purity at $62.41 \% \mathrm{v} / \mathrm{v}$. In the effective adsorption period, the purity of the ethanol effluent 
gradually decreased to $62.01 \% \mathrm{v} / \mathrm{v}$. As shown in Figure 3, after the $150^{\text {th }}$ minute, the effluent concentration of the ethanol-water mixture gradually dropped, and it reached its initial concentration in the $270^{\text {th }}$ minute. This point is called the saturation point or penetration time and is the point at which none of the adsorbents are able to adsorb the adsorbate, so the ethanol effluent concentration goes back to what it was originally. The penetration time is calculated from the time the ethanol effluent starts to come out of the adsorption column $(\mathrm{t}=0)$ to the time when the ethanol concentration is equal to the initial ethanol concentration $(t=n)$.

To further investigate the effect of ethanol influent concentration on the adsorption process, an experiment was conducted with an influent ethanol concentration of $10.72 \%$ $\mathrm{v} / \mathrm{v}$ using the zeolite $3 \mathrm{~A}$ adsorbent. The highest ethanol effluent concentration that was achieved from the adsorption process was $33.27 \% \mathrm{v} / \mathrm{v}$. Figure 3 shows that the effective adsorption period lasted 105 minutes. After this period, the adsorbent was gradually saturated, and it reached its saturation point in the $210^{\text {th }}$ minute. At that time, the ethanol effluent concentration value was approximately equal to its initial value, which was $10.89 \%$ $\mathrm{v} / \mathrm{v}$. An increase in the ethanol effluent concentration was found in both experiments, with the ethanol influent concentration equal to water and lower than water. This phenomenon shows that at ethanol influent concentrations equal to water and lower than water, the adsorbent selectivity for water is more dominant in the mass transfer process between adsorbate and adsorbent. The factors that influence the dominance of the adsorbent's selectivity for water are the internal mass transfer between water and adsorbate and the water concentration gradient. The internal mass transfer between the water and the adsorbate allows the water to penetrate into the pores of the adsorbent because of their molecule size. The water concentration gradient can be explained by Fick's first law, where the water concentration gradient is greater than the ethanol concentration gradient, so the mass transfer flux of water is also greater.

In the third experiment, a variation of the zeolite $4 \mathrm{~A}$ adsorbent was used in the column with the same volume as was used in the previous study. The same sampling time and flow rate as the previous experiment were also used. A similar result was observed in experiment three, where there was a significant increase in the ethanol effluent concentration. Figure 3 shows that the adsorption process with zeolite $4 \mathrm{~A}$ and an ethanol influent concentration of $50.31 \% \mathrm{v} / \mathrm{v}$ reached its highest ethanol effluent concentration at $60.41 \% \mathrm{v} / \mathrm{v}$, with 135 minutes of effective time. With an ethanol influent concentration of $50.31 \% \mathrm{v} / \mathrm{v}$, the adsorbent, zeolite $4 \mathrm{~A}$, reached its saturation point in the $255^{\text {th }}$ minute. For the ethanol influent concentration variation of $10.72 \% \mathrm{v} / \mathrm{v}$, the highest ethanol effluent concentration reached was $29.89 \% \mathrm{v} / \mathrm{v}$. The effective time was 90 minutes, then the adsorbent was gradually saturated, and it reached its saturation point in the $255^{\text {th }}$ minute.

From Figure 3, it can be concluded that increasing the water concentration in the influent stream increases the effectiveness of the adsorption process. The adsorption processes of both zeolite $3 \mathrm{~A}$ and $4 \mathrm{~A}$ with the variations of ethanol influent concentrations of $50 \% \mathrm{v} / \mathrm{v}$ and $10 \% \mathrm{v} / \mathrm{v}$ can form breakthrough curves that align with theory. If the adsorbent reaches its saturation point, it can no longer absorb any adsorbate molecules, and this phenomenon is indicated by the value of $\mathrm{Co} / \mathrm{Ci}$ being equal to 1 -or in other words, effluent concentration of the bed is equal to influent concentration of the bed. Figure 3 shows that the adsorption process of zeolite $3 \mathrm{~A}$ has a longer breakthrough curve because it has longer effective and penetration times. From this phenomenon, it can be concluded that the zeolite $3 \mathrm{~A}$ adsorbent took longer to reach its complete saturation state. Figure 3 shows that experiments with lower initial ethanol $(10 \% \mathrm{v} / \mathrm{v})$ on both zeolites have a shorter effective time. This happens because when the adsorbate (water) influent is increased, the 
more adsorbent surface area will be filled with adsorbate, so that adsorbent will reach its saturation state faster (Han et al., 2010). This is also caused by a greater transfer flux in solutions with a higher water concentration, so that the adsorbent becomes saturated faster. When the saturation time of an adsorbent is faster, the breakthrough curve will be steeper. A steeper breakthrough curve indicates a smaller mass transfer zone, which means that the process has a higher degree of bed utilization. The adsorption process of zeolite $3 \mathrm{~A}$ for both influent concentrations had a lower initial $\mathrm{Co} / \mathrm{Ci}$ value than the adsorption process of zeolite $4 \mathrm{~A}$, which indicated the higher effluent concentration achieved in the adsorption process of zeolite $3 \mathrm{~A}$. A lower Co/Ci value can be taken to indicate a greater capability for absorbing the absorbate.

\subsection{Comparison of Adsorbent Performance}

Several parameters are used to analyze the performance of adsorbents in the process of bioethanol separation with a continuous adsorption process. These parameters include the highest ethanol purity that could be achieved, the effective adsorption time, the penetration time, and the adsorption capacity. Table 1 shows the parameter values obtained from each of the experiments.

Table 1 Adsorbent performance parameters

\begin{tabular}{lcccc}
\hline \multirow{2}{*}{ Parameter } & \multicolumn{2}{c}{ Ethanol Influent 50\% v/v } & \multicolumn{2}{c}{ Ethanol Influent 10\% v/v } \\
\cline { 2 - 5 } & Zeolite 3A & Zeolite 4A & Zeolite 3A & Zeolite 4A \\
\hline $\begin{array}{l}\text { Highest Ethanol Purity (\% } \\
\text { v/v) }\end{array}$ & 62.41 & 60.41 & 33.27 & 29.89 \\
\hline $\begin{array}{l}\text { Effective Adsorption Time } \\
\text { (min) }\end{array}$ & 150 & 135 & 105 & 90 \\
\hline $\begin{array}{l}\text { Penetration Time (min) } \\
\begin{array}{l}\text { Adsorption Capacity } \\
\text { (g water adsorbed/g }\end{array}\end{array}$ & 270 & 255 & 210 & 210 \\
\hline adsorbent) & 0.2418 & 0.2014 & 0.3598 & 0.3095 \\
\hline
\end{tabular}

Zeolite adsorbents have regular pore structures, which allow water to penetrate easily (Laksmono et al., 2017). Both zeolite 3A and 4A are synthetic zeolites. Synthetic zeolites are developed in laboratories to meet the specifications and structure of a molecular sieve. In terms of hydrophilic properties, zeolite $3 \mathrm{~A}$ and $4 \mathrm{~A}$ have a low $\mathrm{Si} / \mathrm{Al}$ ratio that is equal to 1 and contain monovalent cations where the zeolite $3 \mathrm{~A}$ structure contains potassium cations and the zeolite 4A structure contains sodium (Yamamoto et al., 2012). There are differences in the surface characteristics of zeolite $3 \mathrm{~A}$ and $4 \mathrm{~A}$, including the pore diameter and the surface area. These differences affect the performance of the adsorbent. As shown in Table 1 , the adsorption process using zeolite 3A can achieve a higher ethanol purity for both ethanol influent concentrations. The difference in the ethanol purity achieved is influenced by the pore diameter of the adsorbent. The zeolite $3 \mathrm{~A}$ adsorbent has a pore diameter of 0.3 $\mathrm{nm}$, while the zeolite $4 \mathrm{~A}$ adsorbent has a pore diameter of $0.4 \mathrm{~nm}$. Water has a molecular diameter of $0.28 \mathrm{~nm}$ so it can easily penetrate into the pores of both adsorbents, while ethanol has a molecular diameter of $0.44 \mathrm{~nm}$, making it more difficult to penetrate into the adsorbent with smaller pores. As a result, zeolite 3A has a higher selectivity.

The effective adsorption time parameter is mainly influenced by the surface area of the adsorbent. Adsorption processes using zeolite 3A have a longer effective time for both the $50 \%$ and the $10 \% \mathrm{v} / \mathrm{v}$ ethanol influent concentrations. The same result was observed for the penetration time parameter in the experiment with the ethanol influent of $50 \% \mathrm{v} / \mathrm{v}$, 
with the zeolite $3 \mathrm{~A}$ adsorbent having a longer penetration time. However, in the experiment with the ethanol influent of $10 \% \mathrm{v} / \mathrm{v}$, both types of adsorbent had the same penetration time. According to BET data for zeolite adsorbent with a diameter of 3-5 mm, zeolite $3 \mathrm{~A}$ has a slightly larger surface area of $815 \mathrm{~m}^{2} / \mathrm{g}$ than zeolite $4 \mathrm{~A}$, which has a surface area of 727 $\mathrm{m}^{2} / \mathrm{g}$ (Al-Asheh et al., 2004). A larger surface area allows more adsorbate to penetrate into and fill adsorbent surfaces.

In order to calculate the adsorption capacity of each adsorbent, the following equation was used:

$$
\text { Adsorption Capacity }=\frac{\sum \Delta C \times \Delta t \times Q \times \rho}{W}
$$

where $\Delta C$ is the difference between the effluent and influent concentrations expressed in $\% \mathrm{v} / \mathrm{v}, \Delta t$ is the sampling duration expressed in minutes, $Q$ is the flow rate expressed in $\mathrm{ml} / \mathrm{min}, \rho$ is the density expressed in $\mathrm{gr} / \mathrm{ml}$, and $W$ is the total adsorbent mass of the bed expressed in gr. Adsorption capacity itself is expressed in gr water adsorbed/gr adsorbent. The amount of adsorbate that can be adsorbed is influenced by the nature of the adsorbate, the nature of the adsorbent, and the initial concentration. The surface area of the adsorbent was the factor that most influenced its capacity to absorb the adsorbate. The greater the adsorbent surface area, the greater the adsorption capacity. This can be seen in Table 1, where the adsorption capacity of the zeolite $3 \mathrm{~A}$ adsorbent, which has a larger surface area, is greater than the adsorption capacity of the zeolite $4 \mathrm{~A}$ adsorbent. Another factor that also affects adsorption capacity is the adsorbate influent concentration, where the greater the concentration gradient between the adsorbate and the adsorbent, the greater the mass transfer flux. This can also be seen in Table 1, where the adsorption capacity at the ethanol influent concentration of $10 \% \mathrm{v} / \mathrm{v}$ is greater than the adsorption capacity at the ethanol influent concentration of $50 \% \mathrm{v} / \mathrm{v}$.

\section{Conclusions}

The separation of the ethanol-water mixture was conducted using a continuous fixed bed with the $3 \mathrm{~A}$ and $4 \mathrm{~A}$ variations of synthetic zeolite as adsorbents. The ethanol-water mixture flowed into the bed at a $10 \mathrm{ml} / \mathrm{min}$ flowrate with influent concentration variations of $50 \% \mathrm{v} / \mathrm{v}$ and $10 \% \mathrm{v} / \mathrm{v}$. Samples of the ethanol effluent were taken every 15 minutes for 300 minutes to determine the concentrations, which were plotted on a breakthrough curve that is expressed in $\mathrm{Co} / \mathrm{Ci}$ as a function of time.

The breakthrough curve illustrated that the adsorption process with a lower initial ethanol concentration $(10 \% \mathrm{v} / \mathrm{v})$ had a higher degree of bed utilization, which is indicated by a steeper breakthrough curve. Zeolite $3 \mathrm{~A}$, which has a larger surface area, had a longer effective adsorption time ( 105 and 150 minutes) and a greater adsorption capacity $(0.2418$ and $0.3598 \mathrm{gr}$ water adsorbed/gr adsorbent) than zeolite 4A. The pore diameter of zeolite $3 \mathrm{~A}$ is closest to the size of water molecules, so it is more selective for water, which results in a higher ethanol purity $(62.41 \% \mathrm{v} / \mathrm{v}$ and $33.27 \% \mathrm{v} / \mathrm{v})$ as compared to the ethanol purity achieved with zeolite $4 \mathrm{~A}(60.41 \% \mathrm{v} / \mathrm{v}$ and $29.89 \% \mathrm{v} / \mathrm{v})$.

To develop adsorption technology for separating ethanol-water mixtures, further studies investigating the operation conditions that influence the adsorption process, such as temperature, bed height, and flow rate, should be carried out. In addition, studies examining adsorbent variations also need to be conducted to find adsorbents with better performance. 


\section{Acknowledgements}

This research has been funded by Hibah PUTI Prosiding 2020 Universitas Indonesia, Contract Number NKB-1108/UN2.RST/HKP.05.00/2020. The authors would also like to thank the Sustainable Energy Laboratory DTK UI for its remarkable contribution in providing material and equipment for this research.

\section{References}

Al-Asheh, S., Banat, F., Al-Lagtah, N., 2004. Separation of Ethanol-Water Mixtures using Molecular Sieves and Biobased Adsorbents. Chemical Engineering Research and Design, Volume 82(7), pp. 855-864

Chen, S., Yue, Q., Gao, B., Li, Q., Xu, X., Fu, K., 2012. Adsorption of Hexavalent Chromium from Aqueous Solution by Modified Stalk: A Fixed-Bed Column Study. Bioresource Technology, Volume 113, pp. 114-120

Frolkova, A.K., Raeva, V.M., 2009. Bioethanol Dehydration: State of the Art. Theoretical Foundations of Chemical Engineering, Volume 44, pp. 545-556

Han, R., Wang, Y., Zhao, X., Wang, Y., Xie, F., Cheng, J., Tang, M., 2010. Adsorption of Methylene Blue by Phoenix Tree Leaf Powder in Fixed-Bed Column: Experiments and Prediction of Breakthrough Curve. Desalination, Volume 245(1-3), pp. 284-297

Kulprathipanja, S., 2010. Zeolites in Industrial Separation and Catalysis. Weinheim, WILEYVCH Verlag GmbH \& Co. KGaA

Kusrini, E., Wu, S., Susanto, B.H., Lukita, M., Gozan, M., hans, M.D., Rahman, A., Degirmenci, V., Usman, A., 2019. Simultaneous Absorption and Adsorption Processes for Biogas Purification using $\mathrm{Ca}(\mathrm{OH})_{2}$ Solution and Activated Clinoptilolite Zeolite/Chitosan Composites. International Journal of Technology, Volume 10(6), pp. 1243-1250

Laksmono, J.A., Sudibandriyo, M., Haryono, A., Saputra, A.H., 2017. Development of Porous Structured Polyvinyl Alcohol/Zeolite/Carbon Composites as Adsorbent. In: IOP Conference Series: Materials Science and Engineering, Volume 201, Penang, Malaysia

Laksmono, J.A., Pangesti, U.A., Sudibandriyo, M., Haryono, A., Saputra, A.H., 2018. Adsorption Capacity Study of Ethanol-Water Mixture for Zeolite Activated Carbon, and Polyvinyl Alcohol. In: IOP Conference Series: Earth and Environmental Science, Volume 105(1), Bali, Indonesia

McCabe, W.L., Smith, J.C., Harriott, P., 1993. Unit Operations of Chemical Engineering. $5^{\text {th }}$ Edition. McGraw-Hill Book Co

Sudibandriyo, M., Wulan, P.P., Prasodjo, P., 2015. Adsorption Capacity and its Dynamic Behavior of the Hydrogen Storage on Carbon Nanotubes. International Journal of Technology. Volume 6(7), pp. 1128-1136

Vohra, M., Manwar, J., Manmode, R., Padgilwar, S., Patil, S., 2014. Bioethanol Production: Feedstock and Current Technologies. Journal of Environmental Chemical Engineering, Volume 2, pp. 573 - 584.

Yamamoto, T., Kim, Y.H., Kim, B.C., Endo, A., Thongprachan, N., Ohmori, T., 2012. Adsorption Characteristics of Zeolites for Dehydration of Ethanol: Evaluation of Diffusivity of Water in Porous Structure. Chemical Engineering Journal, Volumes 181-182, pp. 443448

Yuksel, F., Yuksel, B., 2004. Technical Note: The Use of Ethanol-Gasoline Blend as a Fuel in an SI Engine. Renewable Energy, Volume 29(7), pp. 1181-1191 